\title{
Arbor
}

\section{La diplomacia de defensa: una aproximación desde España}

\section{Félix Sanz Roldán}

Arbor CLXV, 651 (Marzo 2000), 519-527 pp.

La aplicación de medios militares para evitar la escalada de conflictos, es una actividad que ha venido dándose durante toda la historia. De lo que se trata ahora, en un mundo ciertamente inestable, es de aplicar las capacidades militares a la prevención de dichos conflictos. El apoyo a las misiones diplomáticas en actividades relacionadas con la seguridad, la asistencia al desarrollo armónico de Fuerzas Armadas en las nuevas democracias o el establecimiento de confianza entre miembros de los Ejércitos de diferentes países, no son sino ejemplos de una larga lista de actividades que ejecutan nuestros militares en beneficio de la seguridad. Todas ellas se incluyen bajo el nombre de Diplomacia de Defensa, actividad a la que las Fuerzas Armadas españolas prestan una especial atención.

Para explicar el concepto Diplomacia de Defensa adopto una postura ligeramente heterodoxa. No sólo en el sentido de que lo entiendo de manera diferente a como lo hacen los dos grandes países -Estado Unidos y Reino Unido- que la han incluido en sus esquemas nacionales de seguridad y defensa, sino también porque discrepo sobre la novedad del concepto. Acepto que es de nuevo cuño pero, en caso alguno, podría aceptar que las acciones que configuran la diplomacia de defensa son nuevas. El empleo de medios militares para evitar que se produzcan conflictos, o para darles solución en los momento iniciales de su desarrollo, se ha aplicado durante toda la historia. 
Es cierto que hoy vivimos en un mundo en el que la seguridad colectiva está menos estructurada de lo que parece. La eficacia de las organizaciones internacionales de seguridad es más que dudosa y sólo alguna excepción - pienso en la OTAN - aporta verdadera seguridad a sus miembros. También lo es que están apareciendo nuevos riesgos, a los que es difícil hacerles frente de forma tradicional y que preocupan por su capacidad de alterar nuestra forma de vida. Si a ello se añade que hoy se considera vivir en paz como un bien fundamental, no debe extrañarnos que todos los esfuerzos para lograr dicha paz, y mantenerla, sean de singular importancia.

Durante la década de los 90 se ha hecho un mayor uso de la diplomacia para la resolución de conflictos que en cualquier otra época anterior. Si se hiciera necesario poner un ejemplo, podríamos servirnos del hecho de que, durante la década de los 90, se han firmado tres veces más tratados y acuerdos relacionados con la paz y la seguridad que en los treinta años anteriores. Esta década también ha visto a la diplomacia y a la fuerza, unidas en actividad inusitada, resolviendo asuntos de seguridad de muy diversa índole y poniendo fin a crisis cuya solución inicial parecía muy difícil.

En naciones como la nuestra la diplomacia de defensa debe ser un instrumento mas de la acción exterior del Estado y, por tanto, ha de estar muy ligada a la política exterior, en los aspectos particulares, y no únicos, de la prevención de conflictos. Sólo enmarcada en la gran diplomacia del Estado tiene posibilidad de sobrevivir. Por sí sola no se entiende.

La definición norteamericana pone el acento en los Acuerdos y Tratados bilaterales o multilaterales, en el ámbito de la defensa, al explicar lo que entiende por diplomacia de defensa:

Entendemos por diplomacia de defensa al empleo sin coacción, en tiempo de paz, de los recursos necesarios de la Defensa para el logro de objetivos nacionales específicos, básicamente a través de la relación con otros.

El Reino Unido, en cambio, la define en un marco más amplio, sin que descarte de forma radical el uso de fuerzas militares, aunque sí parece descartar claramente las operaciones militares propiamente dichas. Dice así:

Proporcionar fuerzas para la ejecución de determinadas actividades, bajo la dirección del Ministerio de Defensa, para terminar con hostilidades, construir y mantener la confianza y ayudar en el desarrollo de fuerzas 


\section{La diplomacia de defensa}

armadas que operen bajo parámetros democráticos, con lo que se hace una contribución eficaz a la prevención y resolución de conflictos.

Ambas adolecen de rasgos que podrían estar incluidos en un desarrollo más actual del concepto. Tal es la aplicación de la fuerza militar como apoyo a la diplomacia tradicional en los períodos iniciales de una crisis, con actividades militares que incluyan cierto tipo de operaciones. La línea que divide las operaciones militares de aquellas de apoyo a la diplomacia es muy delgada, pero, aun así, creo adecuado hablar también de diplomacia de defensa en un escenario en el que, aunque la verdadera protagonista es la diplomacia tradicional, sus propios recursos estén prácticamente agotados y necesiten, por tanto, de alguna capacidad adicional que solo pueden aportar las organizaciones militares o los miembros de las Fuerzas Armadas. No pensamos que la diplomacia militar sustituye a la tradicional, sino que la complementa de algún modo, y el protagonismo de la primera en la prevención y resolución de conflictos debe manifestarse sin duda alguna.

Del «empleo sin coacción» de la definición norteamericana, se pasa a la «aportación de fuerzas» del concepto británico para «prevenir y solucionar» los conflictos. A todo ello podríamos añadir algo más: el apoyo a la diplomacia tradicional en los momentos iniciales de una crisis, para obligar a las partes a sentarse y negociar. Tanto en el conflicto de Bosnia-Herzegovina, como en el más reciente de Kosovo, se hizo uso de demostraciones de fuerza para apoyar a la diplomacia tradicional. No quiero decir con esto que las acciones de bombardeo que allí se ejecutaron puedan clasificarse como "diplomacia de defensa», pero sí otras como la aprobación de planes de contingencia y la preparación de fuerzas para su ejecución, la aceptación de un despliegue multinacional, el sobrevuelo de la capital de un Estado por un número importante de aviones armados o los mas recientes ejercicios, en el ámbito de la Asociación para la Paz, en Albania y Macedonia, con participación de fuerzas de nuestra Brigada de Cazadores de Montaña.

En cambio, no creo que en la diplomacia de defensa puedan incluirse las operaciones militares tradicionales, incluso aquellas que no son las clásicas de guerra, como pueden ser las de establecimiento o mantenimiento de la paz, las de ayuda humanitaria y otras de este carácter tan conocidas y tan valoradas hoy por la opinión pública, y ello pese a ser muy numerosas. Tampoco la presencia permanente de fuerzas en algún posible Teatro de Operaciones o puntos que pudieran ser origen de conflictos. Si así lo aceptásemos, los Estados Unidos de América, con su despliegue permanente en Corea, estarían actuando «en 
diplomacia» de forma continua. Una cosa es que esas fuerzas pudieran actuar bajo el esquema que estudiamos y otra bien diferente es que, de forma continuada, estén actuando en beneficio directo de la diplomacia tradicional norteamericana.

\section{Una definición española de Diplomacia de Defensa}

Al contrario que los ejemplos citados del Reino Unido y de los Estados Unidos de América, España aún no ha definido formalmente lo que entiende por diplomacia de defensa, lo que no quiere decir que no venga ejecutando actividades propias de ella en numerosos ámbitos, muchas con singular éxito. Si queremos definirla, hemos de partir de una idea básica, ya enunciada, y de gran utilidad para este fin: La diplomacia de defensa es un complemento de la diplomacia tradicional y ejecuta las actividades que le son propias para apoyarla. Por tanto, e inicialmente, todas cuantas acciones ejecuten las estructuras españolas de defensa en beneficio de la diplomacia tradicional es diplomacia de defensa.

Esta simplificación, que no lo es tanto, nos lleva hacia la consideración de todos aquellos documentos que configuran nuestra Política de Defensa y Seguridad. El de mayor nivel es la Directiva de Defensa Nacional que señala, entre otros, los siguientes objetivos básicos:

- Consolidar la presencia de España en las organizaciones internacionales de seguridad y defensa, asumiendo plenamente las responsabilidades y compromisos derivados de su participación en ellas.

- Que las Fuerzas Armadas españolas estén plenamente capacitadas para contribuir, en la medida de lo posible, a la seguridad colectiva y colaborar en el mantenimiento de la paz y estabilidad internacionales.

El desarrollo posterior de la Directiva de Defensa Nacional ha dado origen a una larga serie de documentos de los que se extraen las acciones concretas a ejecutar por el Ministerio de Defensa, en su conjunto, y por nuestras Fuerzas Armadas en particular. Todas ellas están contenidas en las «Directrices para la Política de Defensa de España» que pronto se verán difundidas para conocimiento de todos cuantos la cuestión interese y para cumplimiento de aquellos encargados de desarrollarlas. Encontramos, sin agotarlas, varias que apoyan la diplomacia tradicional: 
- Impulsar el diálogo y la cooperación, como medidas más adecuadas para garantizar la estabilidad internacional, con especial atención al dialogo con los países del área mediterránea.

- Apoyar y participar en las iniciativas conducentes al mantenimiento de la paz y estabilidad mundiales, promovidas y auspiciadas por Naciones Unidas.

- Participar activamente en la puesta en práctica de las medidas de fomento de la seguridad y confianza, promovidas por la Organización para la Seguridad y Cooperación en Europa .

- Respaldar todas la iniciativas de desarme y apoyar la prevención de la proliferación de armas de destrucción masiva y de sus medios de proyección.

- Impulsar las relaciones bilaterales y multilaterales con los países del Este y Centro de Europa, de la región mediterránea y con los países iberoamericanos y demás naciones con las que mantenemos vínculos históricos.

De la consideración de todos los objetivos anteriores y desde la perspectiva de que todos, de una forma u otra, están siendo cumplimentados por nuestras organizaciones militares, bajo la dirección del Ministerio de Defensa, podríamos aportar una tercera definición.

\begin{abstract}
Diplomacia de Defensa es el conjunto de actividades que ejecutan las organizaciones dependientes del Ministerio de Defensa y los miembros y Unidades de las Fuerzas Armadas en beneficio de la diplomacia tradicional y que abarcan desde la prevención de conflictos mediante el uso de medios militares, hasta la colaboración con las misiones diplomáticas en sus actividades relacionadas con la seguridad, así como las relaciones bilaterales en el ámbito de la defensa para el establecimiento de confianza, para el apoyo al desarrollo armónico de Fuerzas Armadas $y$ para el mejor entendimiento entre sus miembros.
\end{abstract}

que amplía ligeramente las anteriores para dar cabida a la prevención de conflictos mediante el empleo directo de medios militares lo que, a nuestro parecer, tiene cabida en el concepto diplomacia de defensa.

Las actividades generales que siguiendo esta definición se desarrollan en España son de muy variada índole, pudiendo agruparse en aquellas de apoyo directo a la diplomacia tradicional para el fomento de la seguridad y confianza, las relativas a la prevención de conflictos y las de relación entre las organizaciones militares y fuerzas armadas españolas con las de otros países. 


\section{Fomento de la seguridad y confianza}

No por repetido resulta menos preocupante resaltar que vivimos en un mundo heredero de riesgos de épocas pasadas, alguno de ellos de extraordinaria capacidad de producir daños, como es el caso del arma nuclear. Además han aparecido otros nuevos, de similar capacidad de destrucción, y cuyo control es extremadamente complicado al estar en manos de regímenes sin demasiados escrúpulos, o incluso de actores no estatales, cual es el caso de la proliferación de armas bacteriológicas y químicas, sin olvidar los vectores con los que pueden ser lanzados.

España siempre se ha mostrado más partidaria de la limitación de armamentos y de los regímenes de control del mismo que de las acciones directas y así lo ha expuesto en multitud de foros internacionales y en muchas ocasiones. Para apoyo a esta política ha suscrito diferentes Tratados y Acuerdos, en cuya negociación han participado miembros de las Fuerzas Armadas, junto con diplomáticos españoles. El Tratado FACE, para la limitación de Fuerzas Convencionales en Europa, o la Convención de Ottawa, sobre prohibición de minas contrapersonal, así como la Convención de Armas Químicas o el Tratado de No Proliferación de Armas nucleares, no constituyen sino un ejemplo exiguo de las decenas de tratados de los que España es signataria, en beneficio de la seguridad mundial y a cuya celebración han contribuido de forma notable miembros de las Fuerzas Armadas.

Y si importante ha sido la participación de militares en la preparación y negociación de los Tratados señalados, no menos importante es la participación de medios y unidades de las Fuerzas Armadas en otra misión de singular importancia y que entra de lleno en la nueva diplomacia de defensa: la verificación de los tratados de control de armamento y desarme. De nada servirían los acuerdos para la limitación de un determinado tipo de armamento si después no existiera la posibilidad de verificar el cumplimiento de su contenido. Para el caso de la verificación del Tratado FACE, se han realizado unas 40 inspecciones a países del antiguo Pacto de Varsovia y se han recibido 20 a Unidades españolas en nuestro territorio nacional. Por aplicación de dicho Tratado, quedarán destruidos o inutilizados, a finales del año en curso 551 carros de combate y piezas de artillería españolas, que no volverán a contar en nuestras plantillas de armamento, y más de 58.000 de diversos ejércitos europeos, incluidos los de Rusia y los antiguos miembros del Pacto de Varsovia. 
Todo ello es exponente de una diplomacia de defensa muy activa. Para ejecutarla se ha creado, dependiendo del Jefe del Estado Mayor de la Defensa, la Unidad de Verificación Española,. formada por cuadros de Mando de los tres Ejércitos. Sus misiones se desarrollan exclusivamente en el ámbito de la diplomacia de defensa, como nueva función militar.

\section{Prevención directa de conflictos}

En ocasiones, un despliegue militar de características adecuadas añade fuerza a una acción diplomática, ya sea de tipo negociación o de cualquier otro. Durante años, un despliegue adelantado, aunque débil, de la OTAN ha evitado el ataque directo del Pacto de Varsovia. Del mismo modo, el despliegue norteamericano en Corea, o el movimiento de portaaviones en el Golfo de Taiwán, han contribuido a la estabilidad de la zona. La fuerzas militares, por tanto, reforzaban el mensaje diplomático que se daba en las cancillería y, a veces, la sutileza de la aprobación de un Plan de Operaciones haría desvanecerse a alguna amenaza concreta.

Es cierto que el uso de la fuerza no puede compensar de los errores de la diplomacia, pero también es cierto que ayuda a ésta en el logro de sus objetivos. Nunca la fuerza será el sustituto de la diplomacia, pero no cabe duda de que añade impulso a la búsqueda de soluciones políticas que es, a fin de cuentas, su objetivo fundamental. Creo recordar que Kofi Annan, a su regreso de una misión ejecutada con éxito en Iraq y que evitó el empleo de la fuerza, dijo: «Para que la diplomacia tenga éxito ha de apoyarse en la fuerza».

Determinadas acciones militares, por tanto, se ejecutan exclusivamente para apoyo a la diplomacia y la lista de ejemplos es muy larga. En el caso de España podríamos citar dos casos recientes: nuestra participación en las acciones de la OTAN, previas a Dayton, fue un elemento fundamental para el éxito de la negociación. Del mismo modo lo fue el compromiso de España en el marco aliado sobre la posibilidad del uso de la fuerza, mientras se negociaban los acuerdos de Rambouillet; la decisión de iniciar acciones militares sobre el territorio de la ex-Yugoeslavia, cuando quedó claro que la diplomacia había agotado todas sus capacidades -incluyendo las que aportan las fuerzas militares- fue el recurso final para lograr una solución. 


\section{Relaciones bilaterales y multilaterales.}

Contribuir a la seguridad mediante la relación entre miembros de las Fuerzas Armadas de varios países es una actividad que ha demostrado extraordinaria eficacia. Nuestros Ejércitos son especialmente, activos en el desarrollo de este tipo de actividades. La historia reciente de España, que refleja el paso sin traumas de un régimen autoritario a otro plenamente democrático, nuestra participación plena en estructuras de seguridad internacionales y en la Unión Europea, así como el proceso de la transformación de nuestras Fuerzas Armadas, hacen de España un ejemplo a imitar por muchas naciones que desean vivir procesos históricos similares.

Los naciones de la antigua Unión Soviética han mostrado particular interés en estudiar nuestros procesos de adhesión a la OTAN y a la Unión Europea y han solicitado nuestro apoyo para el desarrollo interno de procesos similares. La transformación de nuestras Fuerzas Armadas ha sido seguida en los países de Iberoamérica. Nuestras capacidades, logradas con un gran esfuerzo, son de interés de los países del Magreb. Explicar a todos ellos cuanto hemos hecho y como lo hemos hecho es una tarea de singular importancia que tiene su verdadero valor cuando en esta explicación participan miembros de los Ejércitos.

Es por esto que, en los últimos años se han suscrito cerca de 250 acuerdos bilaterales de muy diversa índole, que regulan nuestra relación con países de Iberoamérica, Europa Central y Oriental, el Magreb e incluso algunos más alejados, a quienes se ha ofrecido ayuda en los campos relativos al ejercicio del control democrático de las Fuerzas Armadas, reorganización de las estructuras de defensa y militares, cooperación en los procesos de modernización, normalización y definición de reglas y procedimientos y formación militar de Cuadros de Mando. Cada año mas de 150 Oficiales y Suboficiales de Ejércitos de Iberoamérica, Norte de Africa y de Europa Central y Oriental reciben cursos becados en Escuelas y Academias militares españolas. Todo ello sin contar con las actividades de intercambio de Unidades o la ejecución de ejercicios, actividades que contribuyen, de forma singular, a los fines de la diplomacia de defensa.

\section{Conclusión}

No cometemos un error grave al afirmar que, aunque la diplomacia de defensa toma carta de naturaleza en nuestros días, se ha venido 
practicando por personas o Unidades militares durante gran parte de la historia. Si ahora aparece como una nueva función militar no es sino para que quede recogida en los textos que la regulan. Reconociendo que sus actividades son ahora más numerosas que tradicionalmente lo han sido, reconocemos también que es una consecuencia de los esquemas de seguridad que hoy se trazan para que nuestra vida siga discurriendo en paz, a pesar de vivir en un mundo más inestable.

La discusión de hasta donde alcanza la diplomacia de defensa durará tiempo. Siempre entendida como apoyo a la diplomacia tradicional, habrá de determinarse el inicio de su zona de acción en algún lugar situado entre el empleo de la fuerza militar, en su sentido tradicional, y el uso de las capacidades individuales y colectivas de sus miembros para la negociación, la mediación y el fomento de la confianza. Su reto no está en buscar nuevas o importantes misiones, sino en contribuir a la paz y estabilidad a través de un ejercicio dirigido por las cancillerías.

De cualquier modo, no es la definición lo que entretiene esta reflexión, sino lo definido. Nadie podrá dudar de la importancia de las organizaciones militares para el logro y mantenimiento de la paz y la seguridad en el mundo de hoy. Los militares, que conocen el sacrificio que supone para la Nación, y para sí mismos, el empleo de la fuerza, siempre estarán mejor dispuestos a participar en la consecución de soluciones pacíficas a cuyo logro muchos de ellos ya han contribuido. Las nuevas generaciones de Cuadros de Mando se incorporan a la vida activa con las capacidades necesarias para asumir esta nueva función; en las Academias Militares se concede gran importancia al estudio de idiomas -más del $60 \%$ de los cadetes obtiene el despacho de Teniente dominando alguno- y entre los textos de estudio figuran Manuales de Negociación y Mediación. Quizás, durante su carrera, nunca harán uso de sus armas, pero si habrán de hacer uso de sus capacidades en apoyo a la decisión política en la gestión y prevención de conflictos.

En estos días se hace cargo un General español del Grupo de Observadores de Naciones Unidas en Kosovo. ¿Diplomacia de Defensa? 